\title{
HUBUNGAN KADAR TNF- $\alpha$ DENGAN FRAKSI EJEKSI PADA PASIEN GAGAL JANTUNG KRONIK DI BLU/RSUP PROF. DR. R.D. KANDOU MANADO
}

\author{
${ }^{1}$ Leonard K. Moningkey \\ ${ }^{2}$ Starry H. Rampengan \\ ${ }^{2}$ Janry Pangemanan
}

\author{
${ }^{1}$ Kandidat Skripsi Fakultas Kedokteran Universitas Sam Ratulangi Manado \\ ${ }^{2}$ Bagian Ilmu Kedokteran Jantung dan Pembuluh Darah Fakultas Kedokteran \\ Universitas Sam Ratulangi Manado \\ Email: leonardmoningkey@gmail.com
}

\begin{abstract}
In patients with chronic heart failure, increases of the TNF- $\alpha$ and IL-6 concentrations are correlated with the degrees of severity of heart failure symptoms and clinical results. This study aimed to obtain the correlation between the concentration of TNF- $\alpha$ and the ejection fraction (EF) among patients with chronic heart failure. This was an analytic study with a cross-sectional design. As samples, there were 30 patients with chronic heart failure at Prof. Dr. R. D. Kandou Hospital Manado from November December 2012. The results showed that based on TNF- $\alpha$ concentration, there were 15 patients with EF 40-50 \%; 11 patients with EF 31-39 \%; and 4 patients with EF $\leq 30 \%$. The Spearman-rho test showed that there was a negative correlation between TNF- $\alpha$ concentrations and Ejection Fraction among patients with chronic heart failure at Prof. Dr. R. D. Kandou Hospital Manado, with a $P$ value of 0.658. Conclusion: Although there was a negative correlation between TNF- $\alpha$ concentrations and Ejection Fraction among patients with chronic heart failure at Prof. Dr. R. D. Kandou Hospital Manado, it was not statistically significant.
\end{abstract}

Keywords: chonic heart failure, left ventricle ejection fraction, TNF- $\alpha$.

Abstrak: Pada penderita gagal jantung kronik, terjadi peningkatan kadar sitokin pro inflamasi dalam plasma, termasuk TNF- $\alpha$ dan IL-6, berkorelasi dengan derajat keparahan gejala gagal jantung dan hasil klinis. Penelitian ini bersifat analitik dengan pendekatan cross sectional. Sampel penelitian ialah pasien gagal jantung kronis (GJK) di BLU/RSUP Prof. Dr. R.D. Kandou Manado. Penelitian dilakukan pada bulan November-Desember 2012 dengan jumlah sampel sebanyak 30 pasien. Hasil penelitian memperlihatkan bahwa distribusi pasien GJK menurut TNF- $\alpha$ terbanyak pada pasien dengan fraksi ejeksi 40-50\% yaitu 15 orang (50\%), dan paling rendah pada pasien dengan fraksi ejeksi $<30 \%$ yaitu 4 orang. Hasil uji Spearman-rho menunjukkan bahwa terdapat korelasi negatif antara TNF- $\alpha$ dan fraksi ejeksi pada pasien gagal jantung kronik di BLU/RSUP Prof. Dr. R. D. Kandou Manado tetapi tidak bermakna secara statistik dengan $P=0,658$ ( $>00,05)$. Simpulan: Walaupun terdapat korelasi negatif antara konsengtrasi TNF- $\alpha$ dan fraksi ejeksi pada pasien gagal jantung kronis di BLU/RSUP Prof. Dr. R. D. Kandou Manado, tetapi tidak bermakna secara statistik.

Kata kunci: Fraksi Ejeksi Ventrikel Kiri, Gagal Jantung Kronik, TNF- $\alpha$ 
Gagal jantung secara sederhana berarti kegagalan jantung untuk memompa darah dalam jumlah yang cukup untuk memenuhi kebutuhan tubuh, keadaan ini dapat terjadi akibat dari semua kondisi kemampuan jantung untuk memompa darah. ${ }^{1}$ Gagal jantung kronik adalah sindrom atau kumpulan gejala dimana ketidakmampuan jantung untuk memompa darah yang mengandung oksigen ke berbagai jaringan penting pada tingkat tekanan pengisian ventrikel yang memicu efek progresif dan meluas yang mempengaruhi struktur dan fungsi jantung dan organ-organ lain di seluruh tubuh. ${ }^{2}$ Faktor resiko gagal jantung sangat bervariasi tergantung dari populasi yang diteliti. Di negara-negara berkembang antara lain berupa faktor resiko berupa penyakit katup jantung, kekurangan gizi, dan infeksi (trypanosomiasis) menjadi faktor resiko gagal jantung kronik. Di negara maju, antara lain penyakit jantung koroner, diabetes mellitus, dan hipertensi merupakan faktor utama yang berperan terhadap peningkatan resiko GJK. $^{3}$

\section{Sekitar 3-20 per 1000 orang pada populasi mengalami gagal jantung,} prevalensinya meningkat seiring pertambahan usia (100 per 1000 orang pada usia di atas 65 tahun), pada angka ini akan meningkat karena peningkatan usia, populasi, dan perbaikan ketahanan hidup setelah infark miokard akut. ${ }^{4}$ Lebih dari 5 juta orang Amerika Serikat adalah penderita gagal jantung dan 550.000 pasien terdiagnosa menderita gagal jantung setiap tahun. Di Inggris, sekitar 100.000 penderita gagal jantung dirawat di rumah sakit pada usia diatas 55 tahun. ${ }^{5}$ Di Indonesia sendiri belum ada angka pasti tentang prevalensi penyakit gagal jantung, di RS Jantung Harapan Kita, setiap hari ada sekitar 400-500 pasien berobat jalan dan sekitar $65 \%$ adalah pasien gagal jantung. ${ }^{6}$

Tumor Necrosis Factor (TNF) adalah salah satu famili dari sitokin pro inflamasi yang dibentuk dari salah satu respon imun alami. Sitokin ini dalam keadaan normal tidak ditemukan pada miokard, sifatnya responsif terhadap stres, dan terbentuk dalam keadaan hipoksi, reperfusi iskemik, infark miokard atau perubahan mekanik. ${ }^{7,8}$ TNF- $\alpha$ diklasifikasikan sebagai sitokin pro inflamasi yang berperan penting pada respon primer host dan perbaikan jaringan. Pada model eksperimental, sitokin menyebabkan remodeling ventrikel kiri, disfungsi kontraksi akut yang reversibel dan pelepasan reseptor adrenergic miokard. Ekspresi berlebih TNF- $\alpha$ pada jantung menyebabkan kardiomiopati dan kematian prematur. ${ }^{7}$ Pada penderita gagal jantung kronis, terjadi peningkatan kadar sitokin pro inflamasi dalam plasma, termasuk TNF- $\alpha$ dan IL-6, berkorelasi dengan derajat keparahan gejala gagal jantung dan hasil kilnis. Peningkatan kadar TNF- $\alpha$ dalam sirkulasi tampak pada gagal jantung kelas NYHA III dan IV. Selain itu ditemukan juga bahwa TNF- $\alpha$ bertanggung jawab terhadap cachexia pada gagal jantung stadium lanjut. Sebuah substudi, Studies on Left Ventricular Dysfunction, menunjukkan bahwa pada gagal jantung sipmtomatik, kadar TNF- $\alpha$ nya meningkat secara progresif. ${ }^{9}$

Salah satu parameter untuk menilai kemampuan fungsi jantung adalah fraksi ejeksi (EF). Fraksi ejeksi dinilai menggunakan parameter ekokardiografi dengan nilai normal 55\%, dan < 40\% dianggap sudah difungsi ventrikel kiri. ${ }^{4,10}$ Fraksi ejeksi ini mewakili isi sekuncup sebagai presentase dari volume akhir diastolik ventrikel kiri, dimana terdapat dua metode yang diterima secara umum untuk mengukur fraksi ejeksi, yaitu teknik volumentrik dan rekaman M-mode. ACC/AHA (American College of Cardiology/American Heart Association) tidak pernah mengklasifikasikan tingkat keparahan gagal jantung berdasarkan fraksi ejeksi namun disebutkan tentang gagal jantung sistolik ( $\mathrm{FE}<50 \%$ ) dan gagal jantung diastolik ( $\mathrm{FE}>50 \%$ ), hanya studi-studi dengan sampel pasien gagal jantung yang mengelompokkannya berdasarkan fraksi ejeksi, misalnya studi SOLVD, PROMISE, GESICA yang memakai batasan fraksi ejeksi < 35\% untuk gagal jantung yang berat (NYHA III-IV), namun ada juga studi yang memakai batasan fraksi ejeksi $<40 \%$ untuk yang berat. ${ }^{11-13}$

Berdasarkan data diatas didapatkan fakta bahwa fraksi ejeksi menurun seiring dengan meningkatnya kadar TNF- $\alpha$. Hal ini mendorong penulis untuk melakukan penelitian untuk mengetahui bagaimana hubungan kadar 
TNF- $\alpha$ dengan fraksi ejeksi pada pasien gagal jantung kronik.

\section{METODE PENELITIAN}

Jenis penelitian ini bersifat analitik dengan pendekatan cross sectional. Penelitian dilakukan di Poliklinik Jantung BLU RSUP Prof. Dr. R.D. Kandou Manado. Penelitian ini dalam pelaksanaannya dari persiapan, pengambilan sampel, analisis sampel, hingga diseminarkan dilaksanakan dari Agustus 2012 Januari 2013.

Besar sampel diperoleh dengan menggunakan rumus :

$$
n=\left[\frac{\left(z_{\alpha}+z_{\beta}\right)}{0,5 \ln [(1+r) /(1-r)]}\right]^{2}+3
$$

$$
\text { Keterangan ; n: besar sampel }=30
$$

Z $\alpha$ : deviat baku alfa

$$
\text { Z } \beta \text { : deviat baku beta }
$$

\section{r: korelasi}

Sampel diambil berdasarkan kriteria inklusi yaitu penderita GJK yang bersedia dijadikan sebagai subjek penelitian, penderita GJK dengan etiologi penyakit jantung iskemik, penyakit jantung koroner, dan sindrom koroner akut dan LVEF $\leq 50 \%$. Pada kriteria eksklusi yaitu penderita GJK yang tidak bersedia dijadikan sebagai subjek penelitian, penyakit jantung katup, wanita hamil. riwayat atau gejala hipertiroid, penyakit atau kelainan paru seperti tumor paru, TB paru. Variable penelitian Umur, jenis kelamin, faktor penyebab gagal jantung kronik, gagal jantung menurut klasifikasi New York Heart Associaton (NYHA) dan fraksi ejeksi

Pengambilan sampel ini dilakukan dengan cara : 1.) mengumpulkan data kasus secara analitik dengan menggunakan data primer berupa pemeriksaan secara langsung yaitu menentukan pasien gagal jantung kronik dengan klasifikasi kelas NYHA, melakukan permeriksaan laboratorium berupa pemeriksaan darah lengkap, kadar kolesterol, pemeriksaan fungsi hati, pemeriksaan fungsi ginjal, pemeriksaan elektrolit, rontgen, EKG, pemeriksaan echocardiografi untuk menentukan fraksi ejeksi dengan menggunakan Esaote my Lab 50, dan melakukan pemeriksaan untuk menentukan kadar tnf- $\alpha$ dengan menggunakan kit Quantikine ELISA Human TNF- $\alpha$ Catalog no: DTA00C. 2.) mengolah data berdasarkan variabel penelitian dan disajikan dengan cara menyusunnya dalam bentuk tabel, grafik dan persentase. 4.) melakukan konsultasi dengan dosen pembimbing. 5.) penyusunan dan pengetikan naskah akhir. 6.) menelaah kembali naskah.

\section{.HASIL PENELITIAN}

Penelitian dilakukan dalam kurun waktu 2 bulan terhitung mulai dari tanggal 1 November 2012 sampai dengan tanggal 31 Desember 2012, ditemukan total 860 kunjungan pasien dengan diagnosa gagal jantung kronik pada instalasi rawat jalan RSUP Prof. Dr. R.D. Kandou Manado. Ditemukan pula 93 total perawatan untuk pasien dengan diagnosa gagal jantung kronik yang dirawat di instalasi rawat inap RSUP Prof. Dr. R. D. Kandou Manado selama periode waktu tersebut. Dari bagian poliklinik jantung ditemukan 10 pasien yang memenuhi syarat untuk di jadikan sampel penelitian sedangkan di Irina F jantung ditemukan 10 pasien yang memenuhi syarat untuk dianalisa. Hasil penelitian dari data yang telah dianalisa adalah sebagai berikut. 
Gambar 1. Distribusi pasien gagal jantung kronik menurut jenis kelamin.

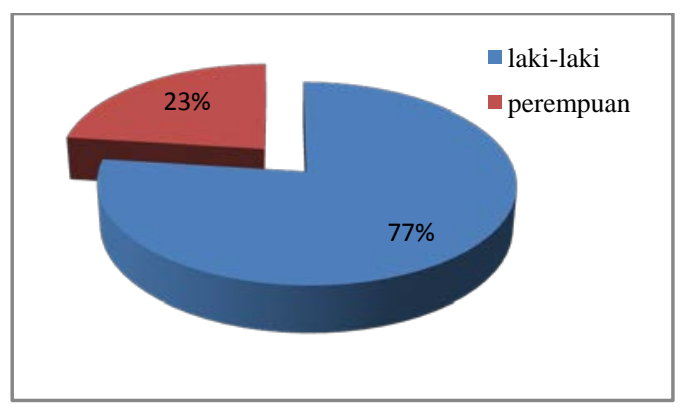

Pada gambar 1. menunjukkan presentase pasien dengan gagal jantung kronik laki-laki sebanyak 23 pasien (77 \%), lebih banyak dibandingkan jumlah pasien perempuan sebanyak 7 pasien (23\%).

Tabel 1. Distribusi pasien gagal jantung kronik menurut umur

\begin{tabular}{lcccccc}
\hline $\begin{array}{c}\text { Golon } \\
\text { gan } \\
\text { Umur }\end{array}$ & \multicolumn{2}{l}{ Laki-laki } & \multicolumn{2}{l}{ Perempuan } & \multicolumn{2}{l}{ Jumlah } \\
\hline & Jumlah & $\begin{array}{c}\text { Presenta } \\
\text { se (\%) }\end{array}$ & $\begin{array}{c}\text { Jum } \\
\text { lah }\end{array}$ & $\begin{array}{c}\text { Presen } \\
\text { tase } \\
(\%)\end{array}$ & $\begin{array}{c}\text { Juml } \\
\text { ah }\end{array}$ & $\begin{array}{c}\text { Presentase } \\
(\%)\end{array}$ \\
\hline $\mathbf{3 1 - 4 0}$ & 0 & $0 \%$ & 1 & $3,3 \%$ & 1 & $3,3 \%$ \\
\hline $\mathbf{4 1 - 5 0}$ & 4 & $13,3 \%$ & 1 & $3,3 \%$ & 5 & $16,6 \%$ \\
\hline $\mathbf{5 1 - 6 0}$ & 9 & $30 \%$ & 4 & 13,3 & 13 & $43,3 \%$ \\
\hline $\mathbf{6 1 - 7 0}$ & 7 & $23,3 \%$ & 1 & $3,3 \%$ & 8 & $26,6 \%$ \\
\hline $\mathbf{7 1 - 8 0}$ & 3 & $10 \%$ & 0 & $0 \%$ & 3 & $10 \%$ \\
\hline Total & 23 & $77 \%$ & 7 & $23 \%$ & 30 & $100 \%$ \\
\hline
\end{tabular}

Pada tabel 1. diatas menunjukkan kelompok usia 51-60 tahun merupakan kelompok penderita gagal jantung kronik terbanyak dengan jumlah 13 pasien (43,3 \%), dan kelompok umur 31-40 tahun merupakan kelompok yang paling sedikit dengan jumlah 1 pasien (3,3\%).

Tabel 2. Distribusi pasien gagal jantung kronik menurut fraksi ejeksi

\begin{tabular}{lll}
\hline \multirow{2}{*}{ Fraksi Ejeksi } & \multicolumn{2}{c}{ Pasien Gagal Jantung Kronik } \\
\cline { 2 - 3 } & Jumlah & Presentase \\
\hline
\end{tabular}

\begin{tabular}{ccc}
\hline$>\mathbf{5 0} \%$ & 0 & $0 \%$ \\
$\mathbf{4 1 - 5 0} \%$ & 15 & $50 \%$ \\
$\mathbf{3 1 - 4 0} \%$ & 11 & $37 \%$ \\
$\mathbf{2 0 - 3 0} \%$ & 3 & $10 \%$ \\
\hline $\mathbf{2 0} \%$ & 1 & $3 \%$ \\
\hline Total & 30 & $100 \%$ \\
\hline
\end{tabular}

Pada tabel 2. diatas menunjukkan pasien gagal jantung kronik yang memiliki fraksi ejeksi 41-50 \% merupakan kelompok paling banyak dengan jumlah 15 pasien (50\%), sedangkan pasien gagal jantung kronik yang memiliki fraksi ejeksi $>50 \%$ merupakan kelompok paling sedikit dengan jumlah pasien 0 (0\%).

Tabel 3. Distribusi pasien gagal jantung menurut pemeriksaan TNF-Alfa

\begin{tabular}{ccc}
\hline & \multicolumn{2}{c}{ Pasien Gagal Jantung Kronik } \\
\cline { 2 - 3 } TNF-Alfa & & \\
\cline { 2 - 3 } $\mathbf{0}-\mathbf{1 , 7}$ & Jumlah & Presentase \\
$\mathbf{1 , 8}-\mathbf{2 , 9}$ & 5 & $3,3 \%$ \\
$\mathbf{3 - 5 , 9}$ & 13 & $16,7 \%$ \\
$\mathbf{6}-\mathbf{9 , 5}$ & 9 & $43,3 \%$ \\
$\mathbf{>} 9, \mathbf{9}$ & 2 & $30 \%$ \\
\hline Total & 30 & $6,7 \%$ \\
\hline
\end{tabular}

Pada tabel 3. diatas menunjukkan presentase pasien gagal jantung kronik yang memiliki kadar TNF- $\alpha$ 3-5,9 pg/ml merupakan kelompok paling banyak dengan jumlah 13 pasien (43,3 \%) sedangkan pasien gagal jantung kronik yang kadar TNF- $\alpha$ 0-1,7 merupakan kelompok yang paling sedikit dengan jumlah pasien $1(3,3 \%)$.

Tabel 4. Analisis hubungan antara kadar TNF-a dengan Fraksi Ejeksi

\begin{tabular}{ccccc}
\hline & \multicolumn{4}{c}{ Fraksi Ejeksi } \\
\cline { 2 - 5 } TNF-a & & & \\
(pg/ml) & $<30$ & $30-39$ & $40-50$ & $>50 \%$ \\
& $\%$ & $\%$ & $\%$ & \\
\hline
\end{tabular}




\begin{tabular}{ccccc}
\hline $\mathbf{0 - 1}$ & - & - & - & - \\
$\mathbf{1 , 1 - 1 , 7}$ & - & 1 & 2 & - \\
$\mathbf{1 , 8 - 2 , 9}$ & 1 & 1 & 2 & - \\
$\mathbf{3 - 5 , 9}$ & 2 & 5 & 5 & - \\
$\mathbf{6 - 9 , 5}$ & 1 & 4 & 4 & - \\
$\mathbf{> 9 , 5}$ & - & - & 2 & - \\
Total & 4 & 11 & 15 & - \\
& & & $\mathrm{p}=0,658$ signifikan \\
& & & $\mathrm{p}>0,05$ \\
\hline
\end{tabular}

Hasil uji statistik hubungan antara kadar TNF- $\alpha$ dengan Fraksi Ejeksi menggunakan uji korelasi Spearman-rho, menunjukkan bahwa secara statistik ada korelasi negatif antara Fraksi Ejeksi dengan TNF- $\alpha$, dengan nilai koefisien korelasi $r=-0,084$. Makin tinggi kadar TNF- $\alpha$ maka makin rendah Fraksi Ejeksi, tetapi tidak signifikan karena $\mathrm{p}=0,658(\mathrm{p}>0,05)$

\section{PEMBAHASAN}

Dari total 860 kunjungan pasien dengan diagnosa gagal jantung kronik pada instalasi rawat jalan RSUP Prof. Dr. R.D. Kandou Manado selama periode November-Januari 2012-2013. Ditemukan pula 93 total perawatan untuk pasien dengan diagnosa gagal jantung kronik yang dirawat di instalasi rawat inap RSUP Prof. Dr. R. D. Kandou Manado selama periode waktu tersebut. Dari bagian poliklinik jantung ditemukan 17 pasien, dan di Irina $\mathrm{F}$ jantung didapatkan 13 sampel yang memenuhi syarat untuk di jadikan sampel penelitian.

Pada penelitian ini ditemukan perbandingan yang jauh berbeda antara jumlah pasien laki-laki dan jumlah pasien perempuan, dengan persentase jumlah pasien laki-laki (77 \%) lebih banyak dibandingkan dengan jumlah pasien perempuan (23\%). Hal ini mirip dengan hasil yang dilaporkan oleh Stromberg dan Martensson $^{14}$, dimana terdapat jumlah insiden gagal jantung tertinggi pada laki-laki, namun secara keseluruhan prevalensi keduanya mirip.

Makin lanjutnya usia seseorang maka kemungkinan terjadinya penurunan anatomik (dan fungsional) atas organ-organnya makin besar. Dari data yang di peroleh di Poliklinik
Jantung maupun di Irina $\mathrm{F}$ Jantung paling banyak adalah pasien dengan gagal jantung kronik yang berusia 51-60 tahun.(43,3\%) dan pasien yang berusia 61-70 tahun (26,6 \%). Hasil penelitian ini mirip dengan hasil yang dilaporkan oleh Rich MW, ${ }^{15}$ dikatakan bahwa di Amerika Serikat didapati lebih dari 75\% pasien dengan gagal jantung kongestif (CHF) berusia diatas 65 tahun.

Pada penelitian ini ditemukan adanya peningkatan kadar TNF- $\alpha$ pada semua penderita gagal jantung kronik, hal ini sama dengan penelitian yang dilakukan sebuah sub studies Studies on Left Ventricular Dysfunction, menunjukkan bahwa pada penderita gagal jantung simptomatik, kadar TNF- $\alpha$ nya meningkat secara progresif. ${ }^{9}$

Dari hasil analisis didapatkan adanya hubungan antara kadar TNF- $\alpha$ dengan fraksi ejeksi. Semakin tingginya kadar TNF- $\alpha$ maka fraksi ejeksi semakin menurun pada pasien gagal jantung kronik.

Hubungan antara kadar TNF- $\alpha$ dengan fraksi ejeksi pada penelitian ini tidak signifikan, hal ini dikarenakan kurangnya sampel yang dianalisa, dan juga keterbatasan waktu penelitian.

\section{SIMPULAN}

Walaupun terdapat korelasi negatif antara konsengtrasi TNF- $\alpha$ dan fraksi ejeksi pada pasien gagal jantung kronis di BLU/RSUP Prof. Dr. R. D. Kandou Manado, tetapi tidak bermakna secara statistik.

\section{DAFTAR PUSAKA}

1. Guyton AC. Hall JE. Buku Ajar Fisiologi Kedokteran. Edisi ke 11. Jakarta : EGC ; 2007.

2. Greenberg BH. The Medical Management of Chronic Heart Failure in Patients with Systolic Dysfunction. Hosenpud JD, Greenberg BH, editor. Congestive Heart 
Failure. Edisi ke 3. Philadelphia:Lippincott Williams and Wilkins; 2007. hal 621.

3. Squire I. Aetiology and epidemiology of chronic heart failure. Dalam: Kearney M. Chronic Heart Failure. New York: Oxford University Press; 2008. hal 2-4.

4. Gray HH, Dawkins KD, Simpson A, Morgan JM. Lecture Notes: Kardiologi. Edisi ke 4. Jakarta: Penerbit Erlangga; 2005

5. Schocken DD, Bejamin EJ, Fonarrow GC, Krumholz HM, Levy D, Mensah GA, dkk. Prevention of heart failure. Journal Of The American Heart Association. 2008;117:2544-65.

6. Fahri I. Evaluasi Ekokardiografi pada Gagal Jantung Diastolik. 23 Maret 2010 (16 Oktober 2012). Available from: http://www.kardiologiui.com/newsread.php?id=365

7. Mann DL. Pathophysiologi of heart failure. In: Braunwald's Heart Disease, $8^{\text {th }}$ ed. Saunders 2008. 541-560.

8. Opie LH. Mechanism of cardiac contraction and relaxation, in: Braunwald's Heart Disease, $8^{\text {th }}$ ed. Saunders 2008; 526.

9. Chen D, Assad-Kottner C, Orrego C, Torre-Amione G. Cytokines and acute heart failure. Crit Care Med 2008;36:1.

10. Ingram RH, Braunwald E. Dispnea Dan Edema Paru. Dalam: Isselbacher KJ,
Braunwald E, Wilson JD, Martin JB, Fauci AS, Kasper DL, editor. Harrison PrinsipPrinsip Ilmu Penyakit Dalam. Volume 1.

11. Hunt S, Abraham T, Chin M et al. 2009 Focused Update Incorporated Into the ACC/AHA 2005 Guidelines for the Diagnosis and Management of Heart Failure in Adults: A Report of the American College of Cardioligy Foundation/ American Heart Association Task Force on Practise Guidelines Developed in Collaboration with the International Society for Heart and Lung Transplantation. J. Am. Coll. Card. 2009, 53; hal el-e90.

12. Moran A, Katz R, Smith N et al. Cystatin C Concentration as a Predictor of Systolic and Diastolic Heart Failure. J Card Fail 2008, 14. hal 19-26.

13. Carbajal E, Deedwania P. Congestive Heart Failure. Crawford $\mathrm{M}$, editor. In Current Diagnosis and Treatment in Cardiology. McGraw-Hill, second edition, 2003. Hal: 217-47.

14. Stromberg A, Martensson J. Gender differences in patients with heart failure. Eur J Cardiovasc Nurs. 2003; 2(1):7-18.

15. Rich WM. Epidemiology, pathophysiology, and etiology of congestive heart failure in older adults. $\mathrm{J}$ Am Geriatr Soc. 1997; 45(8):968-74. 